\title{
Spontaneous Dramatization as Dialogical Space in the School Context
}

\author{
Federica Pascarella ${ }^{1}$ (D) . Antonietta Vicigrado ${ }^{1}$ (D) Luca Tateo $^{2,3}$ (D) . \\ Giuseppina Marsico ${ }^{1,3}$ (D)
}

Received: 30 August 2020 / Revised: 27 December 2020 / Accepted: 5 January 2021 /

Published online: 25 January 2021

(C) The Author(s) 2021

\begin{abstract}
The use of dramatization as teaching/learning methodology, useful for the improvement of social, emotional, creative skills, and for the acquisition of knowledge on subject matters such as history, is an established field of research and practice. Yet, there are very few studies on children's spontaneous dramatization in educational context and its potential role in development. The term dramatization, as we will use here, refers to the human activity of staging in narrative and ritualistic form, enacted through the whole person and multiple channels, communicative and self-presentation meanings. The school context is a privileged arena to observe spontaneous dramatization between peers and between children and adults. Besides, school everyday routine is often filled with staged dramatizations aimed for instance at building collective identity or providing moral orientation. We propose a new theoretical framework and analyse field observation in kindergarten and primary school to interpret spontaneous dramatization and collective school routines.
\end{abstract}

Keywords Dramatization · Tension · Liminality $\cdot$ Cultural psychology of education · Human development

\section{Introduction: Dramatization as Human Feature}

Since Charles Darwin, the capability to spontaneously dramatize has been considered one of the basic abilities of human evolution that led to the development of ritual, religion, and eventually art (Bedaux \& Cooke, 1999). By looking at the first human artefacts, like the Neolithic cave paintings in Fig. 1, one can imagine a group of kin people gathered around the image, with a narrator performing a mythological, religious, or mundane story. No matter what the topic, one can imagine that the account had been made through a

Federica Pascarella

federicapascarella92@gmail.com

1 University of Salerno, Fisciano (SA), Italy

2 University of Oslo, Oslo, Norway

3 Federal University of Bahia, Salvador, Brazil 


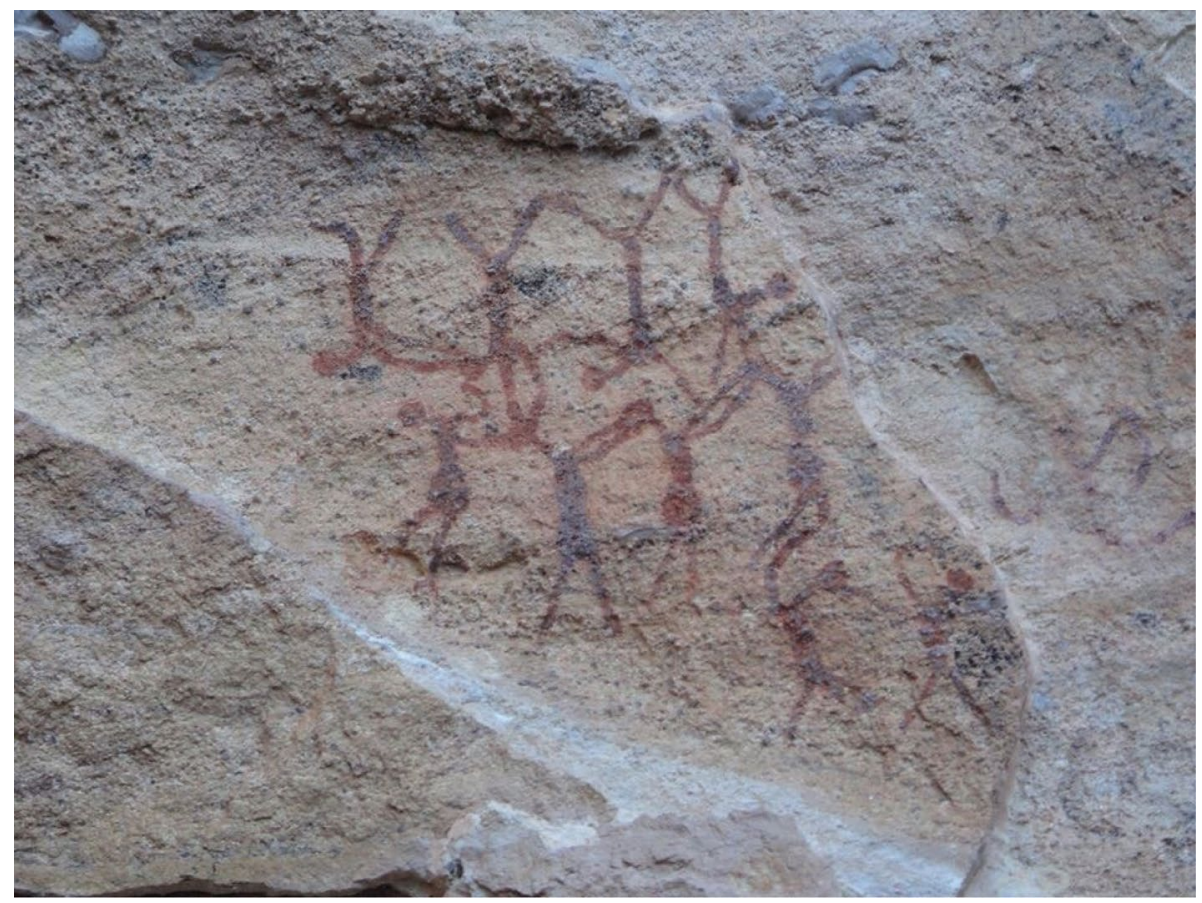

Fig. 1 Cave painting of a group of people in circle, Laas Geel site in Somalia, author unknown, download August 292020 from https://commons.wikimedia.org/wiki/File:Tribo.jpg, Creative Common License

combination of verbal language and gestures, sometimes pointing at the images, and maybe reproducing different sounds.

Regardless of its origins, it is out of doubt that humans have the capability, and often the necessity, to enact their stories, self presentations, and even abstract concepts through acts of dramatization for the sake of information, coordination, and perlocution. Since the 1960s, a new field of studies has been exploring the function of dramatization also in the learning process (Heathcote, 1984; Johnson \& O'Neill, 1991; O'Neill, 1995; Slade, 1955; Wagner, 1976; Way, 1967), with a particular focus on the students motivation and creativity (Slade, 1955; Way, 1967). This interest led to the development of the Drama in Education approach (Wagner, 1976; Johnson \& O’Neill, 1991; Xu \& Tateo, 2020), and the Process Drama approach (Haseman, 1991; Heathcote, 1984; O'Neill, 1995). The use of dramatization as teaching/learning methodology, useful for the improvement of social, emotional, creative skills, and for the acquisition of knowledge on subject matters such as history, is nowadays an established field of research and practice.

There are instead very few studies on children's spontaneous dramatization in educational context (Creekmore \& Madan, 1981; Del Rosso, 1948) and its potential role in development. The theoretical and empirical elaboration that we present is aimed at filling this gap. The term dramatization, as we use it in the present study, refers to the human activity of staging in narrative and ritualistic form, enacted through the whole person and multiple channels, communicative and self-presentation meanings. Besides, human-built environments, including schools, are often arranged as theatrical stages that frame the actions guiding the process of meaning-making (Valsiner, 2020). Children are 
developing selves, and since an early age, there are intra- and inter-individual tensions and ambivalences unfolding (Tateo, 2018, 2019), which are expressed and elaborated through forms of dramatization. We have indeed found that dramatization seems to provide a dialogical and liminal space-time of contact, transformation, and exploration where children can recreate the Self-Other relationship. The school context is of course a privileged arena to observe spontaneous dramatization between peers and between children and adults. Besides, school everyday routine is often filled with staged dramatizations aimed at building for instance a collective identity (e.g. the morning entry rituals such as collective prayer) or provides moral orientation (e.g. the rituals of assessment, the school plays). In order to explore the phenomenon of spontaneous dramatization in social relationships at school, we carried out an observational study in an Italian kindergarten and a primary school over a semester.

\section{Dramatization and Personal Culture: Between Creativity, Representation, and Narrative}

We advance the theoretical concept of spontaneous dramatization as a way to overcome tensions in development and to internalize culture, re-elaborating it in a personal form. The work of mind is often to (re)present in a dramatized form the external world, recalling dialogues, events, and opinions; interpreting; justifying; and anticipating other's actions (Bruner, 1986; O'Neill, 1989). In other words, the imaginative elaboration of nonimaginative mental content is a ubiquitous higher cognitive function (Tateo, 2020): the omnipresent work of imagination, related to memory, fantasy, and intelligence allows to reelaborate content of thought to produce new meanings and anticipate the future. The mind itself can be understood as a stage where a plurality of voices (Hermans, 2006), gifted with incredible acting skills, are playing dialogues and experiencing situations that accompany constructive reflection and identity development.

Like the actors of Commedia dell'Arte, our inner actors are given a rough sketch based on everyday experienced scenarios (Chaffee \& Crick, 2015). Then, our inner actors imitate, wear masks, improvise variations and, in so doing, elaborate an original version of the drama. The capability of the mental actors to arrange in original ways the lived experiences, creating new images and actions, is the mark of combinatory and creative activity (Vygotskij, 1930), which is not the mere reproduction of experienced elements binding the person to its past. Such creative activity is rather the constant (re)production of new infinite variations, the persistent imitation (Baldwin, 1894), which enables the developing person to both internalize cultural practices and values and externalize her own personal version of culture.

Moreover, dramatization presupposes also a distancing from the phenomenal world. Any form of (re)presentation mediated by language, mental images, or embodied cultural forms of acting (e.g. children symbolic play) is a form of voobrazhenie (representation):

a mental faculty, in which the images of perception are transformed through recombination... is a 'stepping-back' from the tangible world of things, a 'take-off', as it were, from the direct impressions we receive through our sense organs. (Suvorov, 1983 , p. 5).

A triple movement is enacted through dramatization (Fig. 2): the person becomes immersed in the phenomenal world, organized as stage for social drama, by becoming 

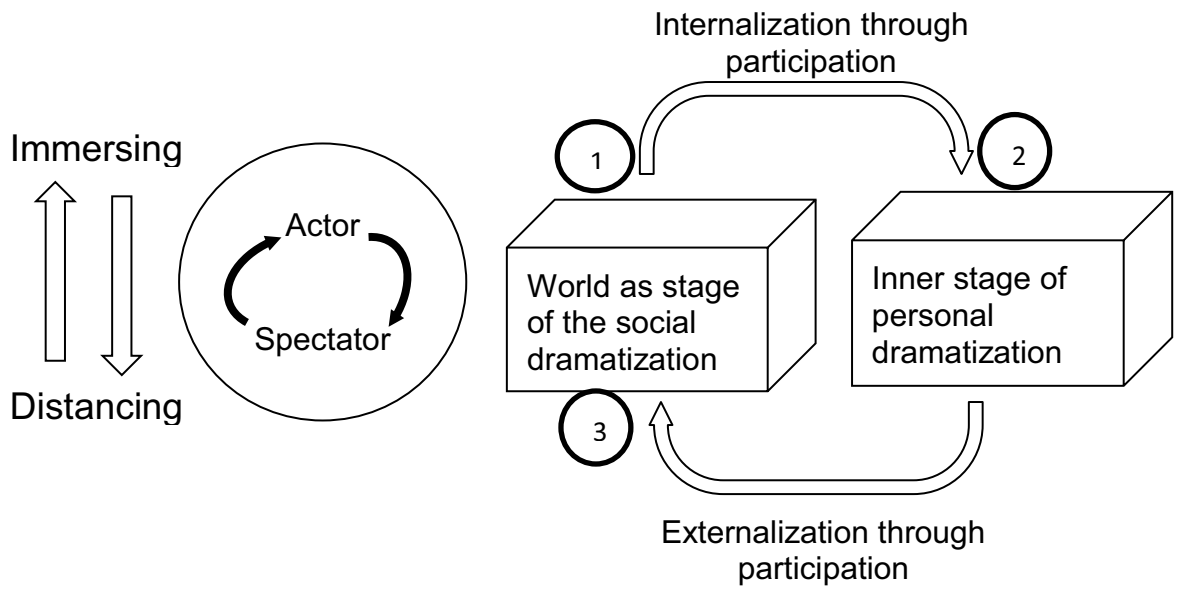

Fig. 2 The dialectic between inner and social dramatization

actor/spectator, then becomes both actor of the inner sketch and distanced audience of the internal play through internalized dramatization; finally, the person reconnects to the phenomenal world with an externalized dramatic act that gives back the personal version of the social drama. These three phases of the movement are marked by the small numbered circles in the Fig. 2. However, as indicated by the circularity of the arrows, the process does not end with the third phase. It continues as a temporary reorganization, reached with the inner and social dramatization, is interrupted by new tensions. The dynamic process is renewed to respond to this tension and achieve a new reorganization. During the entire triple movement, the person becomes the actor of social and inner dramatization and the spectator who reflects on it, alternately.

The creative and representational features of spontaneous dramatization are based on the narrative thinking (Bruner, 1986) and on the imaginative function (Tateo, 2020). The person organizes the world into narrative structures exploring different possible interpretations of the events. She locates experience into a spatial-temporal frame, looking for connections and justification, attributing intentions and motivation to the characters (Bruner, 1986). Narrative structures become the sketch for the inner dramatization and the creative production of new scenarios. Although narrative thinking and imaginative work are universal, the narrative structures and frames are of course framed by the cultural repertoire of symbolic forms, values, and contexts of activity (Coppola, Mollo \& Pacelli, 2019). We all grow up immersed in a web of bedtime stories, religious myths, cartoons and fairy tales, and short stories of the commercials. All these pre-existing and living narratives are often experienced in the form of externalized dramatizations that constitute both the repertoire of potential sketches and the social stage for our own future dramatizations.

Differently from symbolic interactionism (Goffman, 1974), we emphasize the triple movement of intersection between internalization/externalization and immersing/ distancing that creates a double stage for dramatization, leading to a more complex interplay. As aforementioned, the first movement of the triplet is the immersion in the social stage of the phenomenal world. The second step is the internalized dramatization as a semantic re-construction tool of this immersion. The third step represents the reconnection to the world with a new externalized dramatization act, made personal by the precedent 
phase. Therefore, the person is not an actor caught in a play that exceeds her intentionality, just forcing her to wear a mask imposed by the society. The inner and social stages are not totally isomorphic but feed into each other. It is exactly in the tension and dialectics between the social and the inner stage that the elaboration of a personal culture is possible: "an idiosyncratic system of symbols, practices and personal objects" (Valsiner, 2014, p. 214), that maintains similarities with the collective culture while providing the conditions for a personal interpretation and narrative organization of experience.

Dramatization does not end with the intra-mental dimension. Dramatization is externalized through the narrative enactment of personal culture. The person dramatizes her own culture and, through it, becomes herself dramatized narration of her own ontogenetic and phylogenetic history.

Speech and action reveal this unique distinctness. Through them, men distinguish themselves instead of being merely distinct; they are the modes in which human beings appear to each other, not indeed as physical objects, but qua men. (Arendt, 1958, p. 175).

Individual action can be understood as dramatization of the existential narrative, of the life story that inevitably crosses others' stories and the story of the collective culture. Individual dramatization is thus the externalization of the ideational objects that constitute cultures (Valsiner, 2014), that is:

immaterial entities - norms and meanings - [that] entails the internalization/ externalization process: two (or more) persons can "share" meanings only via externalization of their personal sense into the communication process. (Valsiner, 2014, p. 215).

Externalization is framed and guided by social standards that define the window of acceptable conduct: "some of these standards are addressed to the maximally approved, some to the maximally disapproved" (Goffman, 1974, p. 562). Social guidance pushes the person to achieve an ideal, exemplar, form of conduct, a stage dress and a role. Yet, the dialectics between the inner and the social stages creates enough space for the tension between the adherence to the role, in search of comfort and belongingness, and the personal creativity of the person as actor of her own play. We claim that this tension is the fuel for the developmental processes of Self-construction. Through the discussion of an empirical study on children spontaneous dramatization, we will describe the developmental role of tension.

\section{Methodology}

The school is the ideal context to observe the process of spontaneous dramatization and the internalization/externalization of dramatized social roles. School is a human theatrical arena (Valsiner, 2020) and a complex organization. In this micro socio-cultural context, students, teachers, administrative staff, janitors, school managers, and parents are actors playing a role on a stage aimed at educating within national standards.

One of the moments to observe the construction of the social stage and its cultural standards at school is the beginning of the school year. At that time, the child is not yet the pupil, a new role that the developing person will be required to play in the school context. In order to dramatize the role of pupil, the child must first internalize rules and socio-cultural 
meanings of the school into his own existential narrative of the personal culture. Such process generates tensions that lead to the further development of the Self. Such a process unfolds in time, and its study requires an empirical work that captures the process rather than the outcome. Thus, we decided to observe different moments of the school year in a kindergarten and in a primary school of South Italy, located in an inner area of the Province of Caserta, in the Campania Region. Two of the authors have conducted $95 \mathrm{~h}$ of field observation in 2 different moments: in the month of September, when the school year starts, and in the period between January and February, at the end of the first semester. As part of their internship, the 2 researchers observed classroom activities and the moment of the morning entrance at school. A total of 71 children between the age of 3 and 6 years and half, distributed in 2 primary school classrooms and 2 kindergarten classrooms, were observed, including the interactions with their parents, 8 teachers, and 3 special needs teachers. Informed consent was obtained by the adults' participants and the parents of the children involved. No information is provided that can identify the participants, and all names are fictional.

Researchers produced the data through immediate field notes and deferred field diaries. The particular focus was on the observation of events of spontaneous and guided dramatization in the school routine and in the emergence of spontaneous visible tensions in children interaction with peers and adults. Through an interpretive microanalysis of the tension dynamics, we observed how dramatization is used to manage tension and elaborate meanings both individually and collectively. The analysis shows the interplay between spontaneous dramatization and school routines understood as ritual dramatizations.

\section{Entering the School Stage}

The beginning of the school year is the moment in which the teachers try to support children's transformative process of becoming pupils, anchoring the new role in the children's existing existential narrative, during the very first reception activities both in kindergarten and in primary school. Pupils are requested to present themselves both verbally (e.g., "I am a kid, my name is Marco, I am 6, I have brown hair, I am a good boy, I like playing soccer, my parents are Paolo and Anna”) and graphically (e.g., drawing themselves and their families). Making explicit their categorical Self (Lewis $\&$ Brooks-Gunn, 1979) through this collective micro-ritual is a first dramatization. It provides teachers with simple categories to start with. It also allows them to grasp those superficial elements of existential narrative that children are aware of and that they can use to start building and dramatizing the new role. The internalization of the role and its subsequent dramatization is supported by the allocation of the space to be occupied on the classroom stage. Teachers act as directors, distributing seats and giving to the pupils the task of marking their assigned little desk with rosettes of paper, coloured and numbered. The children seem to study each other, take their reciprocal measures ("This is my space, I marked it with my pencil case, my notebooks and the rosette with my name. It is my space-world"). Marking the boundaries of one's daily life and circumscribing the space on the stage of reality allows the dramatization of one's personal culture to take place. The definition of space helps the pupil to appreciate the possibility of maneuvering their role, to internalize its boundaries and possibilities (Marsico, 2018). Similarly, the positioning of objects and furnishings in the environment helps to clarify the child's school existence, enriching her existential narrative with the reality of the classroom. The elements placed 
in the space support the student in building a mental grid of relationships and positions necessary for understanding the social world to which she belongs (Komatsu, 2019).

Another dramatizing function is played by the school uniforms provided by the Italian educational system in the two levels of kindergarten and primary school (Fig. 3). In particular, in the Primary School, the blue apron and the red bow pinned to the chest become the symbol of a new maturity. The colour of the bow distinguishes the different grades (red for the first class, yellow for the second, green for the third, pink for the fourth, and blue for the fifth), conveying the internalization of the sense of belonging to the groupclass and creating a temporal mark of the pupils school life's history. Dresses are never semiotically neutral; they symbolize respect for social norms and become tools for creating personal and collective cultures (Valsiner, 2014). Through the uniform, the dramatization also overcomes the classrooms boundaries by anticipating the school entrance. The social stage is split in a front and a backstage: it is in the dressing rooms of the theatre that the actor wears the character's costume, as it is in the family that the child wears the pupil's outfit. Wearing the apron and pinning the bow to the chest are preparatory phases that expand the boundaries of the staging, create a bridge between school and family environment, anchor the role of pupil to the existential narrative of the child, and transmit moral values. The school uniform, in short, reconfirms itself as an ideal cultural tool for the construction of the personal and collective dimension of the pupil's new role. The dialectic between the social and the personal meanings can be externalized in different ways by the children. Uniforms can be personalized by sewing small patches or by rolling up the sleeves. Stronger dramatic actions can be performed, such as the refusal of wearing the school uniform that we observed in the case of A. and F., two 5-year-old pupils of the kindergarten who often wore coloured T-shirts. This violation can be interpreted as a declaration of will and the rejection of a role that pupils/actors feel imposed by a reality that does not belong to them ("I don't like the school uniforms, my t-shirts look better", "Why do teachers get to decide? I want to decide what to wear"). This behaviour was also justified by children's parents ("The child decides how to dress, otherwise we can't leave the house", "We can't think about the school uniform too"). For this, teachers had to clarify
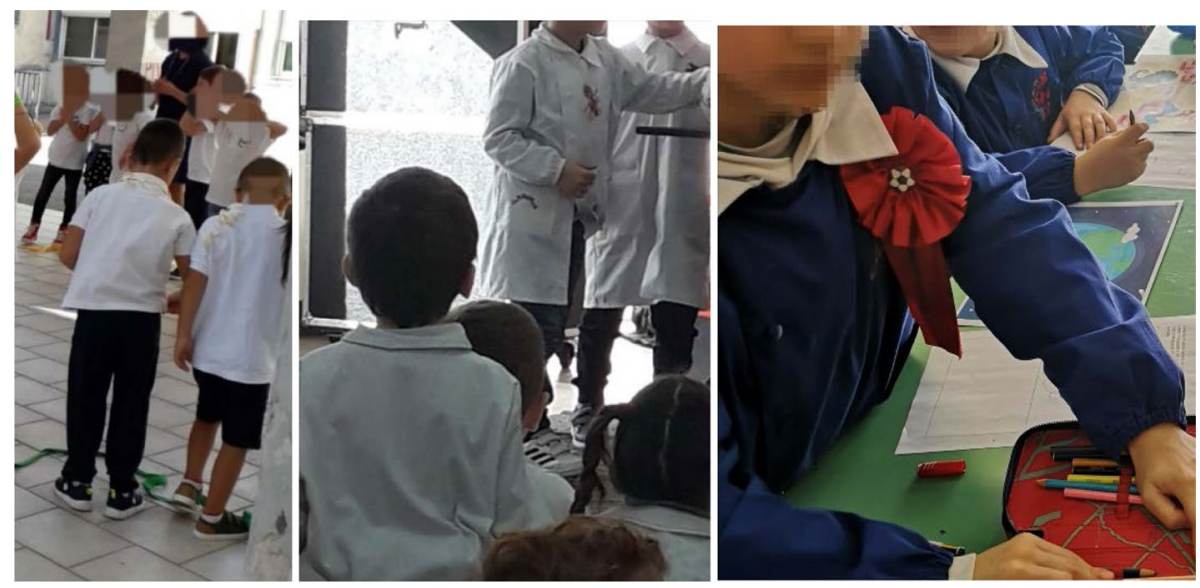

Fig. 3 Three different types of school uniform. The first is the school uniform used at the beginning of the year (black trousers and white t-shirt), the second is that of kindergarten (white apron), and the third is that of primary school (bow and blue apron) 
the importance of the uniform for the construction of the students' school identity ("It's important to respect the common rules in order to become conscious citizens, respectful of social norms"; "Belonging to a group also depends on these small steps"). At the end, the teachers' pedagogical reasons won and the parents follow the school rule. A. and F. wore the school uniforms.

\section{School Routines: Shared Dramatizations with a Ceremonial Value}

In the school's micro-contexts, dramatization is also evident during the daily routines that assume a ritualistic and ceremonial value. Routines are recurring episodes that punctuate school's everyday life. They are also predictable structures that encourage the construction of identity within a structured atmosphere: space-time intervals that elicit the transmissivity and re-construction of the dominant cultural system. Routines provide order and stability, suggesting a spatial and temporal pace to pupils that is useful for organizing their emotional experiences. Routines represent a solid ground to start any creative and constructive meaning production. Routines are based on an established ceremonial in which the conventional and repeated use of gestures and words, the orderly chasing of movements, and the precise interweaving of roles orchestrate a collective staging. Kindergarten is especially structured in routinary times and actions. The pupils' morning reception is followed by the beginning of the teaching activities, the lunches, the continuation of the activities, and, eventually, their conclusion. We observed a meaningful day-starting routine: teachers and pupils sang together a simplified and slightly modified version of the sung prayer "Little Angel of my God":

Little angel of my heartwhat are you doing next to me? I am the angel of the Lord, I am the friend of your heart: when you wake and when you sleepalways, always I am with you! Angioletto del mio cuore che fai tu vicino a me? Sono l'angelo del Signore, son l'amico del tuo cuore: quando vegli e quando dormi sempre, sempre son con te!

The singing was accompanied by a simple choreography. Rhythmic gestures represented lyrics: arms that simulated the flapping of angel's wings; hands closed to the chest shaping the word "heart"; folded hands on the cheek to represent the act of sleeping (when you sleep); "bag hands," with fingertips joined and moved with a horizontal and vertical swing, to emphasize the question (what are you doing next to me?); arms wrapped around the body, to simulate a hug (always, I'm always with you!). The routine was a shared dramatization with a strong ceremonial value: music, gestures, physical co-presence, the daily reconfirmation of the community, and the reference to religion were all components of a ceremony, which celebrated a new beginning and conveyed cultural content. The echoic dimension was an essential element of the celebratory dramatization: ceremonies often use music to penetrate the depth of the self, tune individualities to the same social frequency, and convey the internalization of hyper-generalized values and meanings (Valsiner, 2014). Serenity, love, and a sense of protection then transcend the verbal component and are transported into the inner core of the children's psyche thanks to the sound (Valsiner, 2014). Another important element of the ceremonial was represented by the shared gestures. It was permeated by expressive modalities typical of the socio-cultural system, in which school is inserted and teachers are trained. Since the gestures are socially and culturally codified, the teacher's cultural background is decisive for the construction of gestural choreography. Gestures, such as the polysemic "bag hands," were purposefully 
selected, as they belonged to the Italian gestural alphabet (from southern Italy, to be more precise) and could be difficult to understand if removed from the verbal component and translated into a culturally distant school context. The meaning of the activity therefore transcended the mere memorization of the lyrics, conveyed by their daily and chanting repetition. It was rather the glue of class the community, through the promotion of the internalization of the gestural alphabet of the dominant culture.

Another cultural influence in routinary activity was the reference to the religious dimension. The rhyme included Christian images and symbols, which form the teaching staff's main religious background and, largely, the main Italian School ideological influence. Although in the first verse the word "God" was replaced by "heart," as to avoid explicit references, the sacred tone was still present in the reference to the angel and to the generic term "Lord." The religious value of the song could remain in the background; the ceremonial moment did end with the sign of the cross and the accompanying formula ("In the name of the Father, of the Son and of the Holy Spirit. Amen"). A blatant Christian gesture closed the choreography and the ceremony became a liturgy. The activity became the vehicle of a solidary system of beliefs and practices related to sacred things (Durkheim, 2008) and aimed at cultivating the adherence to a single moral community. The rituality of music, gestures, and actions transforms a routine activity into an arena for meeting and negotiating personal and collective cultures. The staging responds to the group's need to re-build itself daily, a rite of passage that allows you to overcome the tension generated by a new entrance to school and lead the group towards a renewed relationality. It represents a liminal space that allows dialogue between the different selves of the children (at school and out of the school; past, present, and future), between the self and the other, and between personal cultures and the collective cultural system.

\section{The Clash Between Personal Dramatizations and Two Types of Tension}

The staging of the Self's personal culture cannot take place separately from that of the Other. Dramatization cannot be only understood in the individual dimension. Dramatized narratives of personal cultures imply each other, meet, and clash, sometimes. People can give life to their own temporary "theatre companies" for the sake of staging fragments of common life and renewing themselves. There is a daily and incessant encounter-clash between existential narratives, an intertwining of different understandings of reality that produces a mutual sharing and construction of meanings. However, this moment of contact between individualities is not without its pitfalls. It leads to the emergence of two types of tension: intra-individual tension and inter-individual tension. Referring to the quadratic unit theorized by Valsiner (2014), we can detect similarities between the intra-individual tension and the tension existing between the two infinites "Past $<>$ Future." Instead, the inter-individual tension coincides with the friction present in the duality of infinities "Internal $<>$ External."

Metaphorically, intra-individual tension is produced by the person acting like a ropewalker advancing in small steps on a tightrope between an already lived past and a still uncertain future. The entire human existence seems to be a perennial movement between the two ends of the rope: an impossible attempt to reach its infinite ends. Intra-individual tension then emerges from the need of dialogue between the past Self, the present Self, and the future Self. The educational process encapsulates this tension within a value-laden framework: education is led by the goal of a desirable imagined child-to-be. However, 
the complexification, precariousness, and multiplication of social roles in contemporary Western societies exacerbate this tension. Many of these future roles are complex and contradictory (e.g. combining maternity and professional career) and require a radical and continuous reconstruction of the self in order to be taken on (Goffman, 1952). It becomes more and more complex to anchor the future Self onto the knowledge of the past Selfand to find in the Other the "sparring partner" who can help in the clear definition of the present Self and in the choice between possible future Selves. This type of tension emerges, for example, from the request to assume the role of "pupil," made to the children since the first days of school. The pupils are immersed in a new flow of pedagogical and social relations. They are required to abandon part of the past Self and to move towards the identity possibilities of the new future Self to integrate into the school context. The need for security, however, produces resistance to change by pushing pupils back into the cradle of the already known.

The inter-individual tension emerges as a necessary complement to the interactions between the different personal cultures played in the social context. There can be two sources of inter-individual tension. Tension can be generated when the members of the same community share a common collective culture, for instance in the case of intergenerational relationships (Tateo, 2019). The relatively similar personal cultures can clash in the act of transmission, as is the case of the parent who passes the symboliccultural system of the context they belong down to the child (Boulanger, Albert \& Marsico, 2020). Tension can also emerge from the meeting between personal cultures built on different collective cultures competing for the affirmation of a symbolic-cultural system over the other. In both cases, tension seems to be generated by an attempt to transmit to the other the ideational objects (Valsiner, 2014) of one's personal culture. Given the influence of the dominant symbolic-cultural system on the construction of identity of children in the school context (i.e., the child must change in schooling), the inter-individual tensions become more evident. The school can in fact be understood as a cultural arena where existential narratives of personal cultures collide with each other and with the collective culture.

The ideal image of a pupil and the choices that school makes regarding the contents, the environments to be structured and the methods, techniques, and tools to be adopted, are an expression of the socio-cultural system. The curriculum and the actors of the schoolcontext then generate a field of tension that affects the child's developmental trajectory. The child must negotiate between her own existential narrative, hitherto mainly formed in the family dimension, and the school dimension. In an attempt to reduce tension and impose their own individual dramatization, children sometimes adopt opposing or aggressive attitudes, imposing acts of will or pressing requests for attention. This is the case of S., a 6-year boy, who dramatized his refusal to the role of pupil and the associated rules, by throwing the shavings of pencils and crayons on the floor, in an attempt to affirm the existential narrative formed in the family microcontext from which comes ("At home, I do this and then mum cleans").

Children often violate the rules even bringing into classroom non-school objects from home (Table 1). For example, E., a 5 and a half pupil, persists in violating the rules by bringings toy cars. These "illegitimate" objects represent for the pupils the link with familiar things, the affirmation of their own existential narrative, the assurance that, after the school break, everything left in the morning will be found intact. In both cases, the prohibition of teachers to bring these objects, generated in the socio-cultural framework of the school context, collides with the pupils' personal culture, producing an inter-individual tension that demands a solution. 
Table 1 A list of some objects that children bring to school violating the school rules \begin{tabular}{l}
\hline "Illegitimate" objects \\
\hline Toy cars \\
Sticker packs \\
Small puppets \\
Rubber balls \\
Plastic dolls \\
Slime (shapeless and viscous substance)
\end{tabular}

Intra-individual and the inter-individual tensions feed into each other and have a common genesis in the person's continuous struggle to coordinate the four infinities (Valsiner, 2014), with the Self at the interface between the duality pair "Internal $<>$ External" and "Past $<>$ Future." The human being is in the balance between the internal and external world, between what has been and what will be. In the school context, for example, the child is pulled between the past Self and the future Self. She can resist the internalization of school rules, imposed by the external environment, but feel the need to adapt to the role. She can enter into conflict with Others who try to draw her into the collective We of the class but seek proximity. She can reject the ideal image of a pupil that the teacher wants to impose on her but need to negotiate her Self, adapting her individual dramatization to the new socio-cultural fabric of school. The tensions cannot but intertwine: they emerge from the joint action of the individual's temporal precariousness and the confounding uncertainty of his relational world. Intra-individual and inter-individual tensions therefore demand a form of reorganization.

\section{Shared Dramatization: Dialogicality and Liminality to Overcome Tensions}

The temporary overcoming of tensions caused by the encounter-clash between individual dramatizations can be realized in shared dramatization. Social encounters are not a zero-sum game. Checkmate is not realistic. Coordinated collective life is made possible precisely by the liminality and dialogicity of the shared dramatization.

According to Stenner (2017), liminality has to do with an experience in human life that involves a temporary suspension of limits allowing a transition to a new set of limits. Liminality, then, concerns the emergence of novelty just at the moment in which "something" is in process of becoming. Shared dramatization can be defined as a liminal space, a socio-cultural border area, in which individuals are led to critical reflection on reality, to the hybridization of personal cultures and collaborative elaboration of new meanings. Shared dramatization makes visible and thus intelligible the internal and external flow of reality, giving access to the field of circumstances, possibilities, delusions and status reversals. For instance, a quarrel between teacher and student can see the latter prevailing over the former, generating a subversion of the ordinary hierarchical relationship. Dramatization processes can be therefore considered liminal (Van Gennep, 1909) as the individual separates himself from the usual social flow; crosses a suspended dimension in which she acquires or transforms the cultural structures; and, finally, uses the renewed self to readjust 
to the social fabric. Hence, the same dialectic movement of immersing and distancing from the ordinary in relation to mental dramatization is at work.

However, liminality is a necessary but not sufficient condition for overcoming tensions. Only dialogue makes it possible to enter a flow in which individuals can reconstruct themselves and their relationships, sharing and reworking socio-cultural systems of meaning. Through dialogue, personal culture reinterprets itself, projecting beyond its own borders and connecting to other personal cultures for the construction of a common reality, a ground of shared meanings of one's own and others' existential narrations. Intraindividual tension can thus be overcome thanks to the dialogue between the different selves. In the liminality of shared dramatization, the present Self can crystallize the past Self to distance itself from it, reflect on it and dialogue with the possible future Self. The dialogue between temporal identities also involves the possible socio-cultural costumes that the subject-actor can wear. Like a prima donna, the present Self wanders among the scenes of the identity theatre, constantly changing its dresses, taking on different social roles to choose the most suitable among them.

In the shared dramatization, a second dialogic process is triggered, aimed at reducing the inter-individual tension. The interacting subjects suspend the reciprocal action on reality, distance themselves from the crystallized flow of experiences and social relationships, and reflect critically and in shared way on the socio-cultural meanings underlying it. They build or rework the meanings together in order to be able to reconnect in a new way to the social fabric of belonging. This is one of the relevant aspects of the drama-based pedagogical approaches. Despite the attempt to impose one's own ideational objects on the other, the tension can in fact be reduced only by the dialogic negotiation of symboliccultural systems. A balanced compromise between personal cultures can be reached or the dominance of one culture over the other recognized, but, in both cases, it is unrealistic to think of a one-way transmission. Both the interacting subjects transform incoming messages and recompose them into new intrapsychic schemes constructively brought into the sphere of accessibility to the others (Valsiner, 2014). The overcoming and mutual feeding of the two types of tension is the way culture is dynamically elaborating meanings.

One episode, occurred in the first year of primary school between the months of January and March, can illuminate the above-described process.

The central node of the class's network of tensions was S., a 6 and a half boy, whose constant provocations generated clashes with teachers and classmates. The significant socio-relational difficulties of $\mathrm{S}$. were expressed through ridiculing the classmates difficulties and throwing small objects (erasers, paper balls, etc.). The pupil seemed to be perpetually engaged in trying to distance himself from the role of good and talented pupil in which the socio-cultural system of the school tried to force him down. He fought those classmates who accepted and better fit into the assigned role. S. was what can be labelled a disruptive pupil. He played an intra-individual struggle between the school-self and the extra-school-self, between the past-self (a Kindergarten pupil whose role implied a less rigid respect for the rules) and the future-self (Primary school pupil). The struggle was at the same time fuelled by the inter-individual conflict with the collective culture expressed by the teacher and by his classmates, who tried to draw him into the collective We.

The spontaneous micro-dramatizations were characterized by a burlesque representation through uncontrollable gestures, words and tone of voice (e.g. emission of acute cries, impetuous movements). The teacher responded to $\mathrm{S}$. dramatization by staging the threat of the father's wrath ("Look, I got your father's phone number from your mother. Should we disturb him with a phone call?"). A shared dramatization was then generated in an arena of confrontation between the two individual micro-dramatizations. S. went on in affirming 
his own existential narrative, the teacher continued to pretend to call into the family ("If you continue, I'll call!"). S.'s will to affirm his extra-school self ironically turned against himself. The family punishment loomed pushing him to surrender ("No, no. Don't call him, I'm good, I'll stop! Please"). The resolution of tensions, due to an apparent yielding of S.'s personal culture against the rules imposed by the collective culture of the school system, was however only temporary. The absence of a real dialogue, able to trigger a true co-construction of cultural meanings, deprived dramatization of its transformative potential. Rules of conduct in the classroom, the educational transposition of social norms, did not appear to be the object of the dialogue. No elaboration of meanings and production of cultural self-organization took place (Valsiner, 2014).

\section{Precarious Overcoming of Tension: The Ideal Generator of Cultural Tension as the Engine of Shared Dramatization}

The achievement of cultural stability, provided by the overcoming of tensions through shared dramatization, is only temporary. Stability is achieved through the integration of new co-constructed meanings into the individual's personal culture and their use in the multiplicity of everyday situations. A new culturally mediated self emerges from the dramatization. However, "the self is not a fortress, but rather a small open city" (Goffman, 1961, p. 165) and the attacks have a transformative value: the city fortifies, the Self develops by redefining itself under new circumstances to resist once again the threats of reality. It is above all the modern, complex, and discrepant social context that causes the Self to undergo continuous tensions and renewals. Overcoming a tense situation leads to a momentary reorganization, whose maintenance requires dramatic work and can be broken by new tensions and recovered thanks to new dramatizations (Fig. 4).

Dramatization is thus not the moment of tension rather the tool to both maintain the Self-organization and to temporary overcome the tension itself. This movement is

Fig. 4 Continuous succession of tension, dramatization, and temporary equilibrium

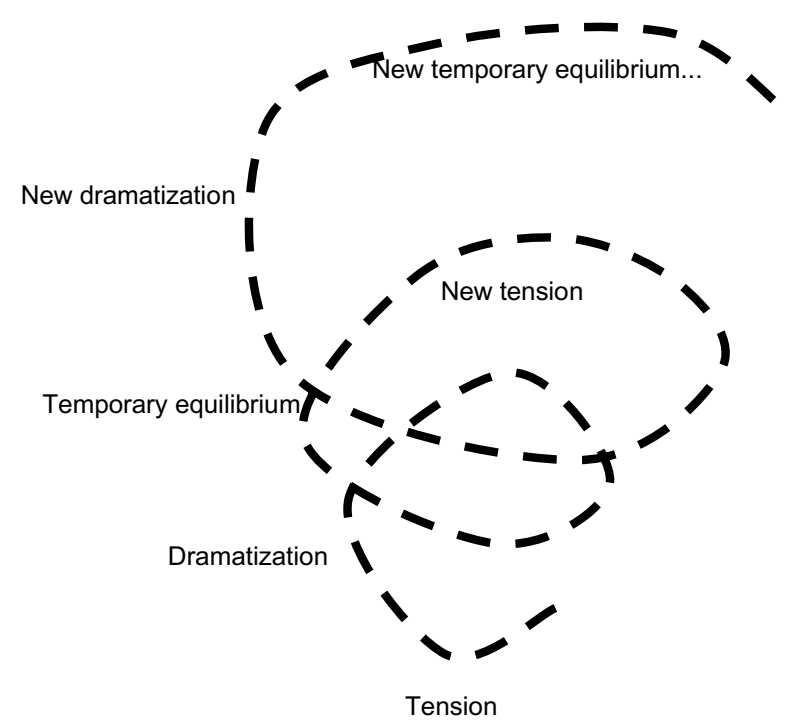


necessary to both the continuation and the innovation of culture. Vygotskij (1925) uses the metaphor of the "short circuit" to describe the genesis and overcoming of the tensions that make a work of art. The ending of a fairy tale, for example, is the moment of the catastrophe, of the exasperation of oppositions, the point of the narrative in which the contradictory elements generate a short circuit that makes the tension explode and exhaust in a cathartic moment. Catharsis is the process of "generalization from personal emotions to higher human truths" (Smagorinsky, 2011, p. 332). Vygotsky's short-circuit metaphor, however, does not account for the continuous creation of new tensions and the innovation of the existing system: "A fuse that has been blown does not generate a new (better) fuse in its place" (Valsiner, 2014, p. 247), it just requires to be replaced with a similar one. We propose instead the metaphor of a dynamo, where the two poles in movement are the Self and the Other. The constant production of difference in electric potential represents the difference between the existential narratives of personal cultures. The encounter/ clash between the Self and the Other generate tension. Overcoming tension is then never completely possible. Intra-individual and inter-individual tensions continue to be generated indefinitely by the difference between the identity poles of an ideal generator of cultural tension, which in return provides the energy for the Self-Other relation to be maintained but in constant motion.

\section{Conclusions}

We have presented a theoretical framework to understand spontaneous and collective dramatization in the child's developing Self. We have stressed the dramatization's socializing value and its role in the co-construction of meanings. The educational opportunities of dramatization have been explored since a long time yet the spontaneous dramatization in the construction of the pupil's Self has not been studied. We have used the theoretical framework of Valsiner's cultural psychology of semiotic dynamics to understand mental dramatization as a semantic re-construction tool that enables the dialectic movement of immersing and distancing from the phenomenal world. We have therefore identified in the dramatized narrative of personal cultures a second type of individual dramatization. Finally, we have discussed the shared dramatization and its elements. They encounter between existential narratives of personal cultures, liminality, and the dialogue between them. The dramatizing work maintains the structure allowing a momentary overcoming of the tensions. We have applied the new theoretical framework on the analysis of field observations in kindergarten and primary school to interpret spontaneous dramatization and collective school routines as forms of shared dramatization with strong ceremonial value.

The theoretical framework we presented can have several applications in the school context. It can also represent the missing theoretical ground that explains the socioeducational potential of dramatization as teaching methodology (i.e., Drama in Education, Process Drama). The characteristics of spontaneous dramatization can also be found in educational dramatization:

- Liminality (Stenner, 2017). The teacher leads the students to a place of transition and transformation, a safe zone where the rules and relational mechanisms of the class are momentarily suspended. In the limbo of educational dramatization, students can experiment with different roles and change their status (e.g. become teachers or 
parents), distancing themselves from the flow of reality, reflecting on it, and engaging in the exploration of possible worlds (O'Neill, 1989). The child then enters the world of circumstances, a world in which he can transform herself, freeze a problem, experiment with alternatives, and shape his own future actions (Heathcote, 1984).

- Tension is the engine of learning through educational dramatization. It is precisely the tension generated by the encounter with life stories (real or fictitious) that triggers the necessary involvement for the active construction of knowledge. Erika Piazzoli (2011) describes different types of dramatic tension. Among them, the one that seems to produce the best educational results is the metaxis. The term, used by Plato to describe the condition of uncertainty inherent in human existence, is used by her to indicate an intra-individual tension generated by the contradictions between role and real identity. In other words, metaxis occurs when people experience the discordance between how they think and act in the drama and how they would normally behave. Erika Piazzoli (2018) gives the example of Emi, a woman who is about to graduate in education. As a future educator, Emi upholds the value of children's access to education. Instead, playing the role of an Italian gypsy child, she feels happy when she can skip school because the school bus does not arrive. For a moment, she forgets her values and does not interpret the situation as a violation of children's rights: happiness for loitering wins. The dissonance between her feelings in the drama and her perceived values produces tension (the metaxis) which leads her to reflect and look at self "from the yes of the others" (Piazzoli, 2018, pag 92). Similarly, in the dramatic situations of the school context, a child may experience the contrast between what the role of pupil requires (e.g. sharing space and materials with classmates) and what she would normally do (e.g. the refusal to share to prevent his stuff from being damaged or lost). In any case, it is precisely this tension that produces the greatest involvement and a more decisive attempt to reflect on the role and meaning of the dramatized experience.

- Transformation through authentic dialogue. The accumulation of dramatic tension motivates the pupil to take action and reflect to overcome the situation-problem. The reduction of tension can only take place, thanks to the liminality of the dramatization and the authentic dialogue. Dialogue can be said to be authentic only if it is transformative, that is, if it induces reflective inner activities and stimulates an investigation that transcends the data immediately available to perception (O'Neill, 1989). Dialogue plays a twofold role: alongside the dialogue between the different roles of the pupils, there is also the one that an individual pupil constructs between her real identity and the role momentarily impersonated. The complexity of the dialogic action is even greater if we also consider the dialogue between the real identities of the pupils. Their real existential narratives are involved in the dialogue as much as their roles.

Finally, we must remember the indispensability of the dialogue between teachers and pupils. This complex interweaving of dialogues is an excellent propeller for the knowledge of the Self and a generator of social transformations. In fact, dialogue supports linguistic development and child socialization, transforming the simple interaction between pupils into sharing and building of a common narrative of life.

Without the existence of narrative and imaginative thinking, the capability of spontaneous dramatization could not emerge ontogenetically. However, as the higher mental functions develop socio-genetically, the study of spontaneous dramatization and shared dramatization provides us with a glance into the way social life is structured in the form collective repertoire of drama. From early age, we internalize social interactions that become the sketches for our Commedia dell'Arte. Without the capability of being at the same time authors, directors, 
actors and spectators of our existential narrative, Self development would maybe not be possible. The characteristics of dramatization, so far described, represent the theoretical foundation for educational dramatization as a tool, of wide use in school, to support selfrealization and socio-emotional development of pupils (Üstündag, 1997). Active participation in unprecedented experiences; the assumption of perspectives different from one's own; the exploration of the emotional dimension; the overcoming of tensions; cooperation and the expression of one's potential find their way in the liminality and dialogicity of a suspended space-time, where possibilities are opened to the developing person.

Open Access This article is licensed under a Creative Commons Attribution 4.0 International License, which permits use, sharing, adaptation, distribution and reproduction in any medium or format, as long as you give appropriate credit to the original author(s) and the source, provide a link to the Creative Commons licence, and indicate if changes were made. The images or other third party material in this article are included in the article's Creative Commons licence, unless indicated otherwise in a credit line to the material. If material is not included in the article's Creative Commons licence and your intended use is not permitted by statutory regulation or exceeds the permitted use, you will need to obtain permission directly from the copyright holder. To view a copy of this licence, visit http://creativecommons.org/licenses/by/4.0/.

\section{References}

Arendt, H. (1958). The human condition. Chicago, IL: University of Chicago Press.

Baldwin, J. M. (1894). Imitation: a chapter in the natural history of consciousness. Mind, 3(9), 26-55.

Bedaux, J. B., \& Cooke, B. (Eds.). (1999). Sociobiology and the arts: problems and prospects. Sociobiology and the Arts. Amsterdam \& Atlanta. GA: Rodopi.

Boulanger, D., Albert, I., \& Marsico, G. (2020). Gerontagogy toward intergenerationality: dialogical learning between children and elders. Integrative Psychological and Behavioural Sciences., 54(2), 269-285. https://doi.org/10.1007/s12124-020-09522-7.

Bruner, J. S. (1986). Actual minds. Possible Worlds, Cambridge, MA: Harvard University Press.

Chaffee, J., \& Crick, O. (Eds.). (2015). The Routledge companion to Commedia Dell'Arte. London and New York: Rutledge Taylor and Francis Group.

Coppola, C., Mollo, M., \& Pacelli, T. (2019). The worlds' game: collective language manipulation as a space to develop logical abilities in a primary school classroom. European Journal of Psychology of Education, 34(4), 783-799. https://doi.org/10.1007/s10212-018-0401-1.

Creekmore, N. N., \& Madan, A. J. (1981). The use of sociodrama as a therapeutic technique with behavior disordered children. Behavioral Disorders, 7(1), 28-33.

Del Rosso, S. (1948). Spontaneous dramatization, a teaching method applied to United States history. Clark University Bulletin, Abstracts of Dissertations, 20, 127-129.

Durkheim, E. (2008). The elementary forms of religious life. Mineola, NY: Dover Publications.

Goffman, E. (1952). On Cooling the Mark Out: Some Aspects of Adaptation to Failure. Psychiatry, 15(4), $451-463$.

Goffman, E. (1961). Encounters: two studies in the sociology of interaction. Indianapolis, IN: Bobbs-Merrill.

Goffman, E. (1974). Frame analysis. An essay on the organization of the experience, Boston: Northeastern University Press edition.

Haseman, B. (1991). Improvisation, process drama and dramatic art; in The Drama Magazine (July), p. $19-21$

Heathcote D. (1984). The authentic teacher: signs and portents; in Johnson, L., O’Neill, C. (1984). Dorothy Heathcote, collected writings of drama and education, London: Hutchinson

Hermans, H. J. (2006). The self as a theater of voices: disorganization and reorganization of a position repertoire. Journal of Constructivist Psychology, 19(2), 147-169. https://doi.org/10.1080/10720530500508779.

Johnson, L., \& O’Neill, C. (1991). Collected writings on education and drama: Dorothy Heathcote. London: Hutchinson.

Komatsu, K. (2019). Meaning-making for living: the emergence of the presentational self in children's everyday dialogues. Cham: Springer. 
Lewis, M., \& Brooks-Gunn, J. (1979). Social cognition and the acquisition of self. New York: Plenum.

Marsico, G. (2018). Development and education as crossing socio-cultural boundaries. In A. Rosa \& J. Valsiner (Eds.), The Cambridge Handbook of Sociocultural Psychology (2nd ed., pp. 302-316). Cambridge, UK: Cambridge University Press.

O’Neill, C. (1995). Drama Worlds: A Framework for Process Drama. Portsmouth, NH: Heinemann.

O'Neill, C. (1989). Dialogue and drama: the transformation of events. Ideas, and Teachers, in Language Arts, 66(5), 528-540.

Piazzoli, E. (2011). Process drama: the use of affective space to reduce language anxiety in the additional language learning classroom. Research in Drama Education: The Journal of Applied Theatre and Performance, 16(4), 557-573. https://doi.org/10.1080/13569783.2011.617104.

Piazzoli, E. (2018). Embodying language in action: the artistry of process drama in second language education. Cham: Palgrave Macmillan. https://doi.org/10.1007/978-3-319-77962-1.

Slade, P. (1955). Child drama. London: University of London Press.

Smagorinsky, P. (2011). Vygotsky's stage theory1: the psychology of art and the actor under the direction of Perezhivanie; in Mind. Culture, and Activity, 18, 319-341. https://doi.org/10.1080/10749039. 2010.518300 .

Stenner, P. (2017). Liminality and experience: a transdisciplinarity approach to the Psychosocial. London: Palgrave.

Suvorov, A. V. (1983). The formation of representation in deaf-blind children. Soviet Psychology, 22(2), 3-28. https://doi.org/10.2753/RPO1061-040522023.

Tateo, L. (2018). Tensegrity as existential condition. In I. Albert, E. Abbey \& J. Valsiner, J. (Eds.), Transgenerational family relations: Investigating ambivalences (pp. 3-20). Charlotte, NC: Information Age.

Tateo, L. (2019). Who wants to keep me a puppet? Pinocchio's tale as a metaphor of developmental processes. Mind, Culture, and Activity, 26(1), 24-40. https://doi.org/10.1080/10749039.2019.1576051.

Tateo, L. (2020). A Theory of Imagining, Knowing, and Understanding. Cham: Springer.

Üstündag, T. (1997). The advantages of using drama as a method of education in elementary schools; in Journal of Hacettepe University Faculty of Education, vol. 13, p. 89-94

Valsiner, J. (2014). An invitation to cultural psychology. London: Sage.

Valsiner. J. (2020). Between the absurd and the enlightened: the Institutionalized Dramaturgy of Education, Human Arenas

Van Gennep, A. (1909). Les rites de passage. Paris: Emile Nourry.

Vygotskij, L. S. (1930). Voobraženie i torčestvo v detskom vozraste; trans. (2004). Imagination and creativity in childhood. Journal of Russian \& East European Psychology, 42(1), 7-97.

Vygotskij, L. S. (1925). The psychology of art. Cambridge, MA: MIT Press.

Wagner, B. J. (1976). Dorothy Heathcote: Drama as a learning medium. Washington: National Education Association.

Way, B. (1967). Development Through Drama. London: Longmans.

Xu S., \& Tateo, L. (2020). Drama-in-Education for understanding: an investigation from the perspective of cultural psychology of semiotic mediation, Human Arenas.

Publisher's Note Springer Nature remains neutral with regard to jurisdictional claims in published maps and institutional affiliations. 